\title{
COMPLICATED ANTERIOR UVEITIS WITH MYCOTIC KERATITIS IN A HORSE
}

\author{
WOUK, A.F.P.F. ${ }^{1}$; GAROTTI, R. ${ }^{2}$; KASECKER, G. G. ${ }^{2}$; ZULIAN I. ${ }^{1}$; SOUZA, A.L. ${ }^{3}$ \\ ${ }^{1}$ Departamento de Medicina Veterinária, UFPR; \\ ${ }^{2}$ Mestrando - Curso de Pós-Graduação em Ciências Veterinárias, UFPR; \\ ${ }^{3}$ Graduando - Curso de Medicina Veterinária - UFPR.
}

A three years old quarter mile mare weighing 500 kilograms and on the last third of pregnancy was received showing signs of severe pain in the left eye. The right eye was normal. This animal was treated, before consultation, with gentamycin eye drops with no success. On the instrumental ophtalmic examination, using biomicroscope, direct ophtalmoscope and flattening tonometer, was observed widespread conjunctivitis, hiperemia involving conjunctive and episclera, edema of cornea, hypopyon, myosis, blackened iris and ocular hypotonia. No changes were seen in the subsequent segment. This signs allowed the diagnosis of anterior subacute uveitis. The treatment, objectifying the ocular imunossupression and maintenance of iris rest, begun. For that it was given: two percent atropine eye drops, tem percent phenylephrin eye drops, one percent prednisone eye drops and one percent prednisone ointment. On the first day of treatment a injection of a two percent solution of bethametasone was given into the sub-conjuctive bulbar space. To the end of fourth week, the eye was calm and the patient was sent home. Three weeks later, the same left eye repeated the same symptoms and the treatment was the same as before except for the replacement of prednisone ointment by a two percent cyclosporine ointment. After 10 days symptoms were gone and the treatment was maintained until the 25th day, when both eyes started to present photophobia, epiphora and blepharospasm. Biomicroscopic examination revealed, in the central area of both corneas, ulcers with a white grayish infiltrate and satellite lesion without vascularization and presenting endothelial plates. It was suspected that ulcers could have a mycotic origin and current treatment was stopped. Cytological exam and biopsy of both the conjunctives and the corneas was carried out. These exams revealed the presence of Aspergillus spp. and Gram positive cocci allowing the diagnosis of mycotic ulcerous keratitis. The treatment was performed by use of itraconazole ophtalmic ointment in a thirty percent dimetilsulphoxide base and one percent cyprophloxacine and condroitine sulphate eye drops. After 15 days of treatment, the signs were gone and only the left eye ulcer still exist. Then it was decided to perform a superficial keratectomy together with a 180 degrees bulbar conjunctival autograft. In this case, probably the imune supressive chronic treatment modified the ocular biota, favoring opportunistic infection with Aspergillus spp. After 45 days of antifungical treatment, the animal left the Hospital both the two eyes showing minimum leucoma but without visual deficit.

Key Words: horse, uveitis, mycotic keratitis, itraconazole. 